\title{
Classic Snodgrass Versus Inner Preputial Inlay Grafted Snodgrass in Distal Penile Hypospadias Repair
}

A.M.El Shazly, H.W.Sherif, S.A.Mohammed and R.G.Omar

Professor of Urology ., Faculty of Medicine, Benha Univ., Benha, Egypt

E-Mail:ahmed.zahran76@yahoo.com

\begin{abstract}
Assessment of the outcome of G-TIP technique in primary distal hypospadias repair in comparison to TIP repair using HOSE score_This study had been performed between June 2018 and June 2019 which included 50 patients all presented to urological outpatient clinic of Benha university hospital -Egypt- with different types of primary distal hypospadias. They were divided into two groups (Group A operated upon using classic Snodgrass TIP urethroplasty and Group B operated upon using G-TIP urethroplasty technique), each group included 25 patients. Circumcised cases or cases with penile chordea more than 30 degree were excluded from the study. Urethral catheter might have been exited set up for particular case week on 10 times. Catch up might have been consistently during 1st, 3rd Also 6th months (3 patients didn't go to the 6th month catch up 2 from one assembly An tip Also particular case starting with the G-TIP assembly B). Mean hose score a t 6th month might have been 15.7 out about 16 Previously, tip and 15.5 Previously, G-TIP (P 0. 52 (NS)). In the tip aggregation those score might have been because of difficulties which incorporated an instance for urethrocutaneous fistula and an instance about meatal stenosis with urethrocutaneous fistula same time in the G-tip an instance from claiming glans dehiscence What's more an instance about gentle remaining chordea. Constantly on effects demonstrated no noteworthy measurable distinction between the two bunches but more agent chance 91. $4 \pm 6.2$ minutes in the G-TIP assembly contrasted with main 85 . $2 \pm 6$. 3 to tip gathering (P 0. $002(\mathrm{~S})$ ), those time used for harvesting, get ready Also inlaying those graft. We finished up that G-TIP urethroplasty is a great elective procedure of the excellent tip repair shed for tantamount comes about Furthermore Despite there were no noteworthy measurable distinction the middle of those 2 gatherings in regards complications, GTIP gatherings demonstrated preferred outcomes Concerning illustration view meatal stenosis Also urethrocutaneous fistula yet all the for longer agent run through.
\end{abstract}

\section{Introduction}

Hypospadias may be a regular genitourinary aberrance influencing 3. 5-4. 5 for every 10000 carry on with births clinched alongside japan [1]. The objectives from claiming hypospadiac surgery incorporate the stronghold of a straight penis for a urethral meatus during those glans tip, those stronghold of a well-vascularized neourethra from claiming sufficient bore with a solid, straight urinary stream and the accomplishment from claiming typical sexual work At those tolerant achieves development [2].

Since Snodgrass at first accounted for Tubularized chiseled plate (TIP) urethroplasty for distal hypospadiac repair shed for 1994,TIP urethroplasty need picked up broad acknowledgement for repairing distal and proximal hypospadias. Those system is simple, versant What's more produces a great cosmea result; however, a few specialized foul issues, including those issue for meatal alternately neourethral difficulties and the compelling reason to standard urethral dilatation, bring. Been pointed crazy. It might be normal that this issue might make possibly a greater amount critical in patients for An even What's more limited urethral plate over for patients with a profoundly grooved Also totally urethral plate because of the more excellent level for assembly obliged [3].

On 2000, Kolon and Gonzales accounted for another procedure from claiming one-stage urethroplasty with An dorsal trim graft utilizing inward preputial skin. This strategy includes entry point from the local meatus of the wind of the urethral plate, and will be particularly successful to decreasing the hazard from claiming meatal or neourethral difficulties over cases of a hypospadiac penis for a even Also limited glans [4].

\section{Patients and methods}

This prospective might have been led for 50 patients who exhibited should Benha school doctor's facility urology division - Egypt- for distal penile hypospadias between june 2018 What's more june 2019. Those cases were separated under two bunches $\therefore$ Bunch A: incorporated 25 patients On whom excellent tip might have been performed.

One assembly B: incorporated 25 patients On whom tip for inward preputial trim graft might have been performed.

Cases for chordea more than 30 degree, Circumcised alternately repetitive cases were excluded from the examine. Every one patients were subjected will complete historical backdrop taking, examination What's more Investigations. Composed assent with point by point portrayal about both systems What's more needed difficulties were demonstrated What's more marked starting with those guardians. Patients were just as randomized utilizing secured envelope that might have been opened intraoperatively following settling on urethral plate entry point.

\subsection{0perative technique}

The greater part methods were performed under general anesthesia with caudal anesthesia for postoperative absense of pain. After get ready the genitalia Also draping, footing suture might have been 
connected of the summit of the glans utilizing 5/0 polyglactin suture. At that point nelatone catheter passed under those hypospadiac meatus.

Boundary entry point beneath those crown might have been done with degloving of the dorsal penile skin. A u-molded skin entry point might have been settled on encompassing those meatus for two paramedian incisions constructed the middle of glans Also urethral plate extending those wind of the urethral plate. Those penis might have been degloved of the penoscrotal intersection What's more simulated erection might have been aggravated utilizing butterfly canula (blue 23 gauge) on evaluate for vicinity for penile chordea which remedied Toward dorsal plication of the corpora cavernosa On short of what 30 degrees.

Dismemberment of the glanular wings starting with underlying corpora cavernosa with 3 o'clock on the exited side What's more on 9 o'clock on the correct side Furthermore of the end of the urethral plate.

Profoundly incising the urethral plate utilizing stevens Tenotomy scissors from the hypospadias opening of the conclusion of the urethral plate distally - down of the tunica albuginea coating those underlying corpus cavernosus. During this venture the body of evidence wrap opened on determine if tip or Grafted tip might a chance to be done.

In instances from claiming grafted tip inward preputial skin join might have been harvested, defatted Furthermore sutured by 6/0 Vicryl sutures of the edges What's more floor of the chiseled urethral plate. Numerous gaps required been carried out in the graft utilizing $3 \mathrm{~cm}$ syringe needle. The period Also width of the graft might have been dead set intraoperatively by the period and width of the chiseled urethral plate Fig (1).

Tubularisation of the urethral plate through a nelatone catheter for proper extent as stated by agdistis of the tolerant Also width of the chiseled urethral plate clinched alongside two layers, primary interfered subcuticular 6/0 Vicryl sutures afterward second constant subcuticular 6/0 PDS sutures without pressure. Spongioplasty required been carried By and large. Neourethral suture transport might have been secured for An dartos pedicle fold utilizing buttonhole system At that point glanuloplasty Fig (2). Urethral catheter might have been exited set up to you quit offering on that one week to 10 days.

The gathered information were tabulated Furthermore broke down utilizing SPSS adaptation 16 delicate ware (SpssInc, Chicago, sick organization). Unmitigated information were exhibited Concerning illustration amount Also rates utilizing chi square $\left(\chi^{2}\right)$ test alternately Fisher's accurate test (FET) for their examination. Quantitative information were tried for typicality utilizing Shapiro- Wilkstest. They were exhibited Similarly as intend \pm standard deviation What's more extent whether regularly distributed, average might have been included for non parametric variables. Scholar " $t$ " test might have been used to examine parametric nonstop variables "around 2 free groups, same time mann Whitney u (ZMWU) test might have been utilized for non parametric ones, recognizing $\mathrm{p}$ esteem huge In 0.05 .

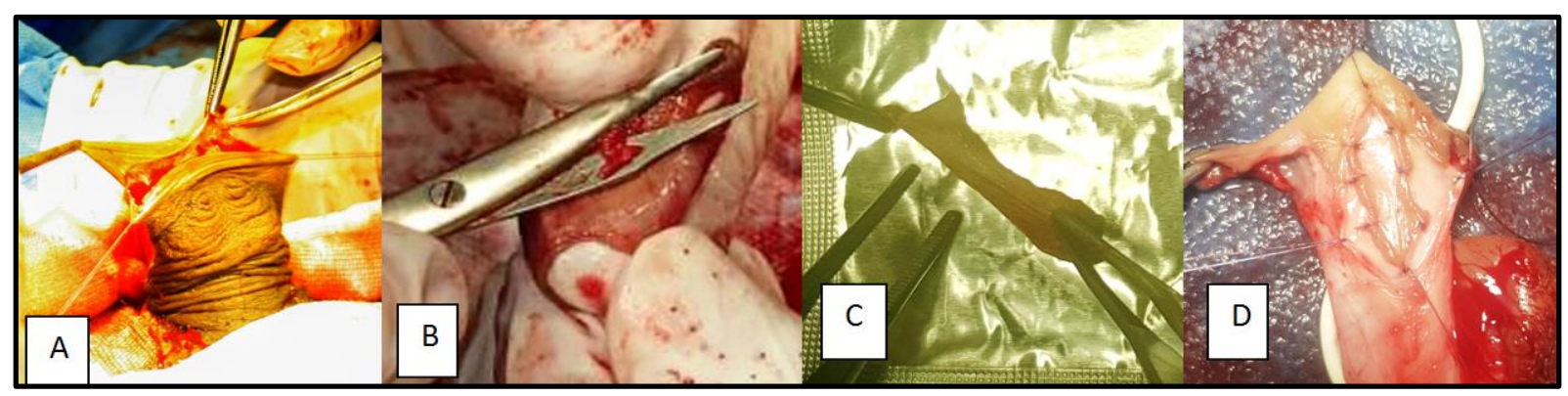

Fig (1) A- Harvesting the graft from the inner preputial skin. B- Graft trimming and defatting. C- Harvested graft ready for inlaying in the incised urethral plate $D$ - Graft sutured by $6 / 0$ Vicryl sutures to the edges and floor of the incised urethral plate

\section{Results}

Total of 50 patients were included in this study of which 25 patients had underwent TIP urethroplasty (group A) and 25 underwent G-TIP (group B). The mean age of group A was $(23.0 \pm 14.8)$ and $(37.8 \pm$ 48.9 ) for group B (P 0.39 (NS)). Meatal location

was coronal in 5 cases, sub coronal in 23 cases and distal in 22 cases. Mild chordea was found in 13 cases Table (1). Transverse glanular diameter was (mean $14.3 \mathrm{~mm}$ in TIP while $15.2 \mathrm{~mm}$ in
G-TIP) (P 0.14 (NS)), urethral plate length was ( mean is $9.7 \mathrm{~mm}$ in TIP group while $11.1 \mathrm{~mm}$ in G-TIP group) (P 0.10 (NS))and urethral plate width was (mean $8 \mathrm{~mm}$ in TIP group and $7.6 \mathrm{~mm}$ in G-TIP group) (P $0.21(\mathrm{NS}))$.

Comparing the two groups as regard operative time shows highly significant statistical difference between the two groups (P $0.002(\mathrm{~S})$ ) being longer in G-TIP group. The mean time was $(85.2 \pm 6.3 \mathrm{~min})$ in group A and (91.4 $\pm 6.2 \mathrm{~min})$ in group B Fig (2) . 


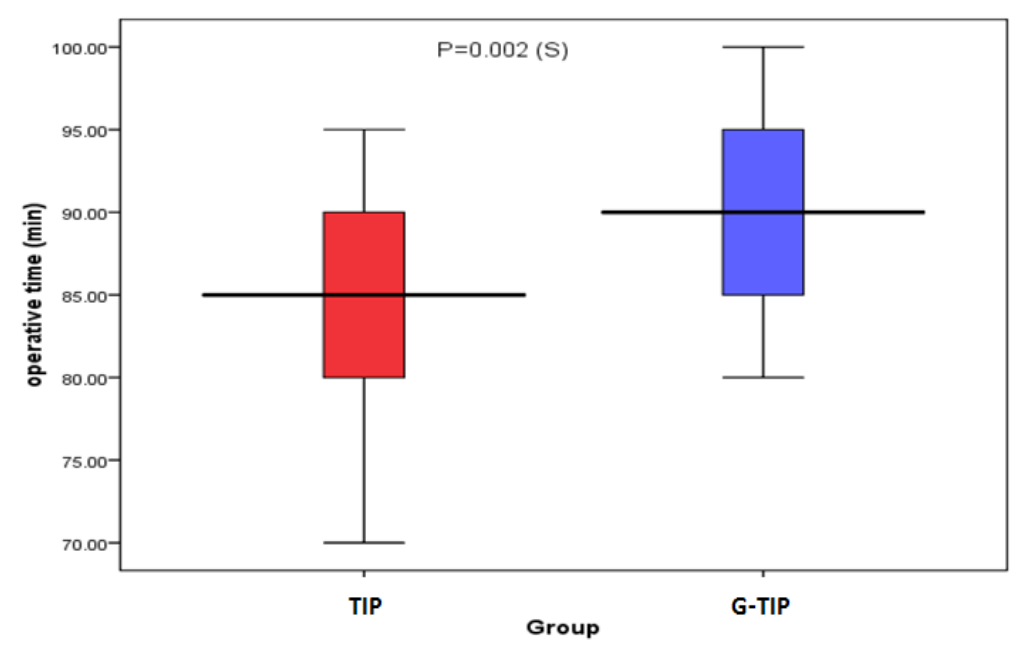

Fig (2) Box plot showing median and range of operative time among the studied groups

Spongioplasty has been done to most cases (14 cases in TIP group and 13 cases in G-TIP group which is not statistically significant). Dorsal plication for 5 cases in TIP group while for 4 cases in G-TIP group (which is not statistically significant).

Results at 2 weeks showed that the meatal location was distal glanular in 25 cases in group A while in 24 in group B, coronal in 1 case of group B (coronal location of the meatus was due to glans dehiscence). Meatal shape was vertical slit in 22 cases of group A and in 21 of group B, circular in 3 cases of group A and in 4 cases of group B. Urinary stream was single in 22 cases of group A and in 23 cases of group B while spray in 3 cases of group A and 2 of group B ( spraying was due to meatal stenosis and glanular dehiscence ). Single sub coronal fistula developed in 3 patients in group A and in 1 patient in group B (P 0.61 (NS)). All the data differences between the two groups were not significant statistically.

Regarding assessment using HOSE score at 2 weeks (erection couldn't be assessed at 2 weeks), the mean score for the meatal location ( 4.0 out of 4 in TIP group while being 3.92 in G-TIP group) (P 0.32 (NS)), meatal shape ( mean score 1.88 out of 2 in TIP and 1.84 in G-TIP group) (P 0.69 (NS)) , urinary stream (mean score of 1.88 out of 2 in TIP group while 1.92 in G-TIP ) (P 0.65 (NS)) and fistula (mean score 3.88 out of 4 in TIP group while 3.96 in G-TIP) (P 0.31 (NS)). Comparing early post operative complications after 2 wks of operation as regard Glans dehiscence (which occurred in one case of G-TIP) (P 1.0 (NS)) (Fig.3), Wound infection, Catheter slippage, Skin sloughing, Fever, Detrusal irritability. All data were insignificantly different between the 2 groups.

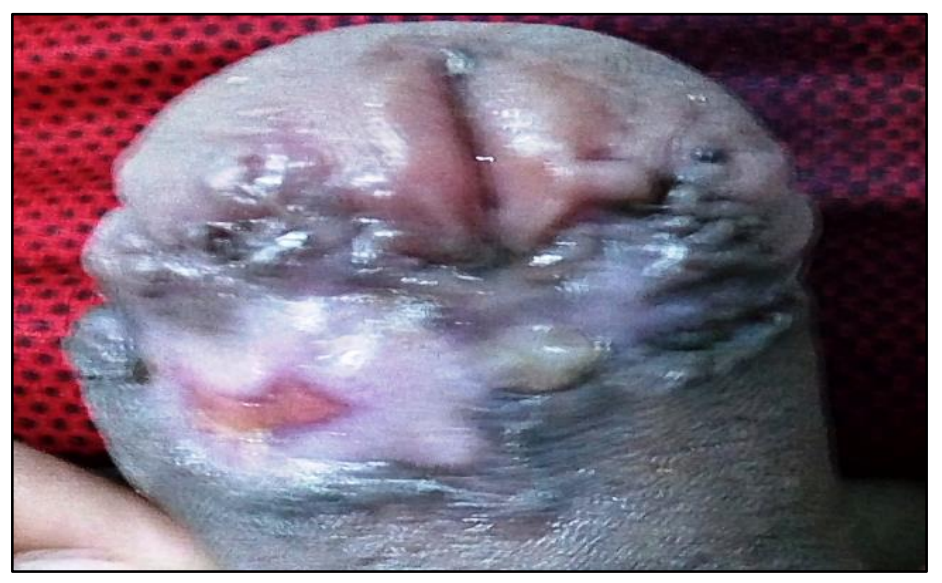

Fig (3) A case of G-TIP at 2 weeks postoperative assessment with glans dehiscence.

Results at 6th month follow up showed that Meatal location was distal glanular in 23 cases in TIP group and 23 in G-TIP group, coronal in 1 case of G-TIP (coronal location of the meatus was due to glans 
dehiscence) (P 1.0 (NS)). Meatal shape was vertical slit in 20 cases of TIP group in 20 of G-TIP, circular in 3 cases of TIP and in 4 cases of G-TIP (P 1.0 (NS)). Urinary stream was single in 21 cases of TIP and in 23 cases of G-TIP while spray in 2 cases of TIP and 1 of G-TIP (spraying was due to meatal stenosis, fistula and glanular dehiscence) (P 1.0 (NS)). Erection was straight in 23 cases of TIP group while in 23 of G-TIP, moderate angulation in one case of G-TIP group ( $\mathrm{P}$ 1.00 (NS)) (Table 1). Single sub coronal Fistula developed in 2 patients in TIP group (The fistula that was found at $2 \mathrm{wks}$ assessment responded to frequent dilatation program and closed spontaneously one in each group (P 0.23 (NS)).

Results at 6th month follow up showed that Meatal location was distal glanular in 23 cases in TIP group and 23 in G-TIP group, coronal in 1 case of G-TIP (coronal location of the meatus was due to glans dehiscence) (P 1.0 (NS)). Meatal shape was vertical slit in 20 cases of TIP group in 20 of G-TIP, circular in 3 cases of TIP and in 4 cases of G-TIP (P 1.0 (NS)). Urinary stream was single in 21 cases of TIP and in 23 cases of G-TIP while spray in 2 cases of TIP and 1 of G-TIP (spraying was due to meatal stenosis, fistula and glanular dehiscence) (P 1.0 (NS)). Erection was straight in 23 cases of TIP group while in 23 of G-TIP, moderate angulation in one case of G-TIP group (P 1.00 (NS)) (Table 1). Single sub coronal Fistula developed in 2 patients in TIP group (The fistula that was found at 2 wks assessment responded to frequent dilatation program and closed spontaneously one in each group (P 0.23 (NS)).

Table (1) Comparing the studied groups regarding frequencies of cosmetic parameters at 6th month.

\begin{tabular}{|c|c|c|c|c|c|c|}
\hline & & \multicolumn{2}{|c|}{ TIP group $(\mathrm{N}=23)$} & \multicolumn{2}{|c|}{ G-TIP group $(\mathrm{N}=24)$} & \multirow[t]{2}{*}{$\mathbf{P}$} \\
\hline & & No. & $\%$ & No. & $\%$ & \\
\hline \multirow[t]{4}{*}{ Meatal location } & Distal glanular & 23 & 100.0 & 23 & 95.8 & \\
\hline & Proximal glanular & 0 & 0.0 & 0 & 0.0 & $1.0(\mathrm{NS})$ \\
\hline & Coronal & 0 & 0.0 & 1 & 4.2 & \\
\hline & Penile shaft & 0 & 0.0 & 0 & 0.0 & \\
\hline \multirow[t]{2}{*}{ Meatal shape } & Vertical slit & 20 & 87.0 & 20 & 83.3 & $1.0(\mathrm{NS})$ \\
\hline & Circular & 3 & 13.0 & 4 & 16.7 & \\
\hline \multirow[t]{2}{*}{ Urinary stream } & Single stream & 21 & 91.3 & 23 & 87.5 & $1.0(\mathrm{NS})$ \\
\hline & Spray & 2 & 8.7 & 1 & 4.2 & \\
\hline \multirow[t]{2}{*}{ Erection } & $\begin{array}{l}\text { Straight } \\
\text { Mild angulation }\end{array}$ & $\begin{array}{c}23 \\
0\end{array}$ & $\begin{array}{l}100.0 \\
0.0\end{array}$ & $\begin{array}{c}23 \\
0\end{array}$ & $\begin{array}{c}95.8 \\
0\end{array}$ & $1.00(\mathrm{NS})$ \\
\hline & Moderate angulation & 0 & 0.0 & 1 & 4.2 & \\
\hline \multirow[t]{3}{*}{ Fistula } & Non & 21 & 91.3 & 24 & 100.0 & $0.23(\mathrm{NS})$ \\
\hline & $\begin{array}{l}\text { Single sub-coronal } \\
\text { Single proximal }\end{array}$ & $\begin{array}{l}2 \\
0\end{array}$ & $\begin{array}{l}8.7 \\
0.0\end{array}$ & $\begin{array}{l}0 \\
0\end{array}$ & $\begin{array}{l}0.0 \\
0.0\end{array}$ & \\
\hline & Multiple or complex & 0 & 0.0 & 0 & 0.0 & \\
\hline
\end{tabular}

Fisher's test was used Regarding assessment using HOSE score at 6th month, the mean score for the meatal location ( 4 out of 4 in TIP group while being 3.91 in G-TIP group) (P 0.33 (NS)), meatal shape ( mean score 1.86 out of 2 in TIP and 1.83 in G-TIP group) (P 0.73 (NS)), urinary stream (mean score of 1.91 out of 2 in TIP group while 1.87 in G-TIP ) (P 0.68 (NS)), erection chordea mean of 4 of 4 in TIP while 3.91 in G-TIP (P 0.33 (NS))and fistula (mean score 3.91 out of 4 in TIP group while 4 in G-TIP) (P 0.14 (NS)). The mean of the total HOSE score was 15.7 out of 16 in TIP and 15.5 in G-TIP (P 0.52 (NS)) (Fig. 4). All data differences between the 2 groups are not statistically significant. 3 patients didn't attend at 6 month appointment.
At the 6th month assessment in the classic TIP (Snodgrass) group, there were two cases of urinary fistula with one of these two cases had meatal stenosis. Another case of group A (classic TIP urethroplasty) had meatal stenosis. So total of 3 cases had complications in the TIP group with success rate of $(86.95 \%)$ with mean HOSE score of 15.7 (98.12\%). 2 fistulas one from each group that appeared at 2 weeks follow up responded well to regular urethral dilatation for one month. In the G-TIP group one case had been complicated with glans dehiscence and another case with residual penile chordea. So success rate was $(91.66 \%)$ in the G-TIP group with mean HOSE score of 15.5 (96.87\%). All results showed no significant statistical difference between the two groups except longer operative time $91.4 \pm 6.2$ minutes in the G-TIP group compared to only $85.2 \pm 6.3$ for TIP group (P $0.002(\mathrm{~S})$ ), the time spent for harvesting, preparing and inlaying the graft. 


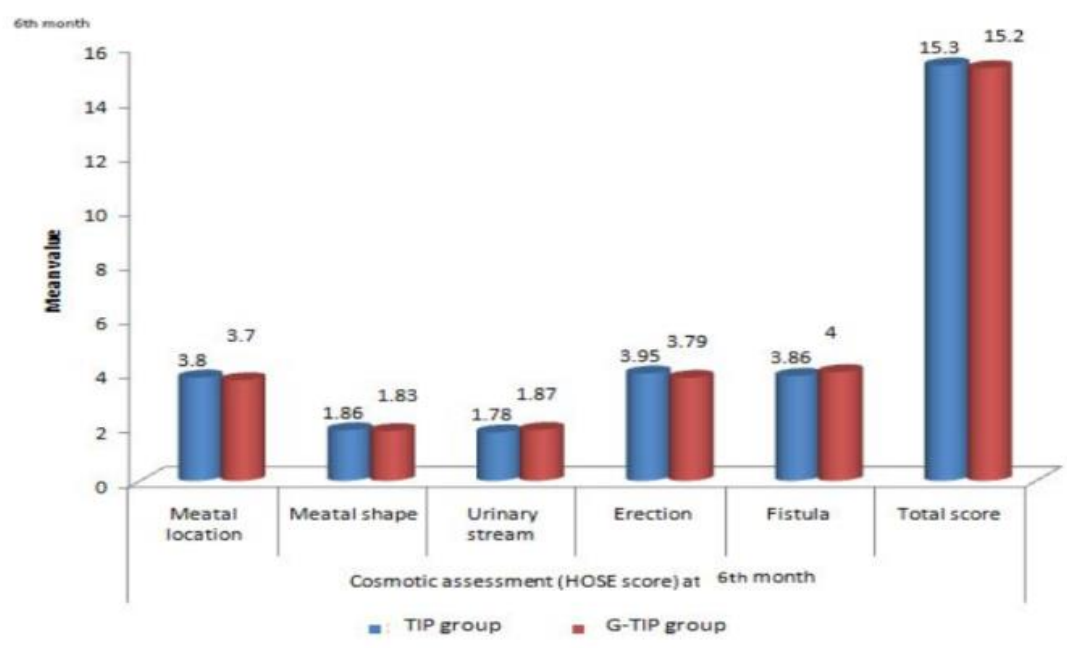

Fig (4) Bar chart showing Cosmetic assessment (HOSE score) at 6th month

\section{Discussion}

Hypospadias is characterized Likewise an inadequate virilization of the genital tubercle, prompting a ectopic opening of the urethra on the ventral angle of the penis, anyplace starting with those glans of the perineum. Its occurrence will be something like $1 / 300$ done live male newborn child births [5].

Surgical repair shed may be those standard from claiming treatment What's more a standout amongst the A large portion regular methods performed Eventually Tom's perusing pediatric urologists. Te deum point about hypospadias repair shed is with attain ordinary urinary Also sexual capacity with beneficial stylish bring about shortages Furthermore fearlessness of the kid [5].

Urethrocutaneous fistula will be the The majority normal Also not kidding muddling of the surgical procedure from claiming hypospadias repair, Furthermore its frequency camwood a chance to be used to judge the accomplishment about hypospadias repair shed [6].

Over 2000, Kolon Also Gonzales news person those procedure about person phase dorsal trim inward preputial graft. They performed this system in 32 patients, Furthermore during 21 months from claiming catch up no tolerant needed meatal stenosis, neourethral stricture, urethrocutaneous fistula or urethral diverticulum. They news person that this strategy is particularly compelling to decreasing the danger about meatal or neourethral difficulties clinched alongside instances of a hypospadiac penis for An level or limited glans, Furthermore a verthandi slit-like neourethral meatus is structured during those glans tip [4].

Over our study, we broke down two methods utilizing 50 (of which 2 instances didn't go to the catch up during 6 months ) instances for essential distal hypospadias separated Previously, two gatherings , one assembly a who underwent tip repair shed What's more aggregation $b$ who underwent G-TIP. Both aggregations were similar Similarly as respect to patients' age, meatus location, length Also width and profundity of urethral plate Furthermore glans width. In this study, Urethrocutaneous fistula formed clinched alongside 2 situations of the tip assembly (one connected with distal meatal stenosis) same time no fistula done G-TIP bunch. However, Factual dissection reveals to that there may be no critical difference between them. Those secondary frequency from claiming fistula in the Snodgrass gathering compared for those dorsal trim graft bunch might make attributable of the resultant urethral stricture What's more meatal stenosis brought about Eventually Tom's perusing optional plan recuperating of the once again cut, which builds those danger from claiming Creating urethrocutaneous fistula.

Meatal stenosis by and large happens Previously, up to $7 \%$ for patients following hypospadias repair shed [7]. Right on time dilatation of the neourethra then afterward hypospadias repair shed may be a handy strategy to the promptly revelation Also medicine from claiming meatal stenosis [8]. In this study, Meatal stenosis happened in the tip gathering Previously, 2 situations same time no instances for meatal stenosis in the G-TIP gathering.

Done our consider in the tip gathering no situations for glans dehiscence happened same time particular case the event in the G-TIP bunch. Glans dehiscence happened auxiliary on wound spoiling as the tolerant dismissed bringing postoperative parental antibiotics as prompted.

In our investigation person case of distal penile hypospadius for gentle chordea What's more in length urethral plate $20 \mathrm{~mm}$ required underwent G-TIP repair shed for phenomenal Generally speaking outcomes but for direct post agent chordea which might be expected with long trim graft contracture Similarly as struck them for Gupta v et al , ( 2016 ) [9]. 
Contrasted with the tip group, the trim internal preputial graft gathering didn't hint at whatever statistically noteworthy contrasts in surgical triumph (being $88 \%$ in the tip gathering since difficulties occured On 3 instances Furthermore 92\% clinched alongside G-TIP Similarly as two situations muddled Toward glans dehiscence Furthermore gentle chordea) Also muddling rates. Those cosmea conclusions (mean score) graded Eventually Tom's perusing those hose were 15.3 done tip bunch What's more 15.2 to G-TIP one assembly. There might have been no huge Contrast "around aggregations for admiration to the cosmea scores ( $p$ 0.98). The main statistically huge distinction the middle of both bunches might have been a more extended agent chance $88.0 \pm 6.2$ minutes in the G-TIP bunch contrasted with best $85.2 \pm 6.3$ to tip one assembly (p 0. 002), the run through used for harvesting, get ready Furthermore inlaying the graft.

Some confinements about our consider must make recognized. Those littler amount for patients to every associate and the generally shorter catch up contrasted with different arrangement might disparage the difficulties. Hence, extra expansive prospective consider may be necessary on secure the specialized foul focuses will abrogate those meatal/neourethral stenosis.

\section{Conclusion}

We reasoned that G-TIP urethroplasty may be a great elective technobabble of the excellent tip repair shed for tantamount effects Also In spite of there were no noteworthy Factual Contrast the middle of those 2 Assemblies viewing complications, G-TIP aggregations demonstrated better effects as see meatal stenosis Also urethrocutaneous fistula Be that as with more extended agent the long run.

\section{References}

[1] N.Kurahashi, M.Murakumo, H.Kakizaki , The estimated prevalence of hypospadias in Hokkaido, Japan. J. Epidemiol; Vol.14,PP.73-7,2004.

[2] G. Manzoni, A.Bracka, E.Palminteri, G.MARROCCO,Hypospadias surgery: When, what, and by whom? BJU Int;Vol.94,PP.1188-95. 2004.

[3] H.Asanuma, H.Satoh, S.Shishido, Dorsal inlay graft urethroplasty for primary hypospadiac repair. Int J Urol;Vol.14,PP.43-7,2007. [4] T.F.Kolon, E.T.Gonzales, The dorsal inlay graft for hypospadias repair.J. Urol;Vol.163,PP. 1941-3,2000.

[5] E.Baillargeon, K.Duan, A.Brzezinski, R.Jednak, M. El Sherbiny, The role of preoperative prophylactic antibiotics in hypospadias repair. Can Urol Assoc J;Vol. 8,PP.236-240,2014.

[6] A.B.Retik, M.Keating, J.Mandell, Complications of hypospadias repair. Urol Clin North Am;Vol.15,PP.223-236,1988.

[7] W.Snodgrass, M.Koyle, G.Manzoni, R.Hurwitz, A.Caldamone, R.Ehrlich, Tubularized incised plate hypospadias repair: results of a multicenter experience. J Urol;Vol.156 (2),PP. 839-841,1996. [8] Z.I.Radojicic, S.V.Perovic, K.D.Stojanoski, Calibration and dilatation with topical corticosteroid in the treatment of stenosis of neourethral meatus after hypospadias repair. BJU Int;Vol.97,PP.166-168,2006.

[9] V. Gupta, S.K.Yadav, T.Alanzi, I. Amer, M.Salah, M.Ahmed, Grafted tubularised incised-plate urethroplasty: An objective assessment of outcome with lessons learnt from surgical experience with 263 cases Arab J Urol;Vol.14(4),PP. 299-304,2016. 